\title{
Relationship between gastric emptying of a solid meal and emptying of the gall bladder before and after vagotomy
}

\author{
J N BAXTER, J S GRIME, M CRITCHLEY, S A JENKINS, AND R SHIELDS \\ From the Departments of Surgery and Nuclear Medicine, University of Liverpool \& Royal Liverpool Hospital, \\ Liverpool
}

SUMMARY Little is known of the temporal and quantitative relationships between emptying of the stomach and of the gall bladder in patients with duodenal ulcer before and after vagotomy. A noninvasive double isotope technique was used to investigate these relationships in 27 patients with a duodenal ulcer, before and after operation - truncal vagotomy and pyloroplasty $(T V+P ; n=15)$ and highly selective vagotomy (HSV; $n=12$ ). A further 25 patients were studied after operation $(\mathrm{TV}+\mathrm{P}, \mathrm{n}=20$ : HSV, $\mathrm{n}=5)$. ${ }^{99} \mathrm{Tc}^{\mathrm{m}}$-EHIDA was used as the biliary tracer and ${ }^{113} \mathrm{In}^{\mathrm{m}}$ bran as the gastric content tracer. In patients with a duodenal ulcer before surgery and in 16 of the 17 patients studied after HSV, the patterns of gall bladder emptying were similar to those previously found in normal subjects. In $60 \%$ of patients after $\mathrm{TV}+\mathrm{P}$, patterns of gall bladder emptying were altered and the onset of gall bladder emptying was significantly delayed $(p<0.001)$ compared with unoperated patients and patients with a HSV. The rate of gall bladder emptying did not correlate with the rate of gastric emptying in any of the patients studied. These observations suggest that $\mathrm{TV}+\mathrm{P}$, but not $\mathrm{HSV}$, causes considerable alteration in coordination of gall bladder and gastric emptying.

There have been no studies in man of the precise relationship between emptying of the stomach and of the gall bladder after vagotomy. Although the effects of truncal vagotomy and drainage on the stomach are well known, ${ }^{1-3}$ those on the gall bladder are still unclear. Thus after truncal vagotomy and pyloroplasty $(\mathrm{TV}+\mathrm{P})$, emptying of the gall bladder has been reported as increased, ${ }^{4}$ decreased, ${ }^{5}$ or unaltered. ${ }^{6}$ The variety of methods used to measure gall bladder emptying, however, may explain some of the conflicting results. Frequently, unnatural stimuli - for example, exogenous cholecystokinin (CCK) have been used to stimulate gall bladder emptying.

In our previous studies of normal subjects, we stimulated gall bladder emptying by a solid meal containing a radiolabel and thus were able to measure gastric emptying and gall bladder emptying

Address for correspondence: Dr J N Baxter, University Department of Surgery, Christchurch Hospital, Private Bag. Christchurch, New Zealand.

Received for publication 11 November 1986. (using ${ }^{99} \mathrm{Tc}^{\mathrm{m}}$-EHIDA scintigraphy) simultaneously. The advantage of a meal is that it brings into play all the stimulatory mechanisms, cephalic, gastric, and intestinal, responsible for gall bladder emptying. Furthermore, alterations in gall bladder motility after operation are more likely to be demonstrated using a meal rather than a single stimulus, such as exogenous CCK, which bypasses the normal control mechanisms.

Alterations in the normal coordinated emptying of stomach and gall bladder after operation - if these were shown indeed - could have important clinical consequences. For example, alteration in the timing of delivery of gall bladder bile to the duodenum may play a role in the aetiology of the fat malabsorption observed in many patients after truncal vagotomy for a duodenal ulcer. ${ }^{8}$

The aim of this study was to define the patterns of gall bladder emptying after a meal and to clarify the relationship between gall bladder and gall bladder emptying in patients with a duodenal ulcer, and 
patients after $\mathrm{TV}+\mathrm{P}$ or highly selective vagotomy (HSV).

\section{Methods}

PATIENTS

Twenty seven patients with a duodenal ulcer awaiting surgical treatment volunteered for a prospective study. These patients were studied before, and at a mean of $7 \cdot 1 \pm 0.4$ months (range 5.5-10.1) after operation. Fifteen of these patients underwent $\mathrm{TV}+\mathrm{P}$ and $12 \mathrm{HSV}$.

In addition, 25 patients were also studied at a mean of 21 years (range 20-36) after operation for duodenal ulcer, TV $+P(n=20)$ and $\operatorname{HSV}(n=5)$. The Royal Liverpool Hospital Ethical Committee gave approval for the study (January, 1982) and informed consent was obtained from each patient.

The dual isotope method used for simultaneously measuring gastric emptying and gall bladder emptying has been previously described in detail. ${ }^{7}$ Each study began at 0900 hours and lasted 120 minutes. The patient lay semirecumbent beneath a large field of view gamma camera (Searle LFOV, G D Searle, Unithoorn, Holland), fitted with a high energy parallel hole collimator and linked to a computer system (Digital PDP 11/34, Maynard, Massachusetts). Each subject received an iv injection of $74 \mathrm{MBq}(2 \mathrm{mCi})$ of ${ }^{99} \mathrm{Tc}^{\mathrm{m}}$-EHIDA $(2,6-$ diethylphenylcarbamoyl-methyliminoadiacetic acid) which was prepared from a commercially available kit (Amersham, UK).

When the counts in a region of interest around the gall bladder reached a relatively constant value (count accumulation less than $1 \%$ per minute), the patient was given a test meal of porridge (Readybrek $^{\mathrm{R}}$ ) mixed with bran labelled with $9.2 \mathrm{MBq}$ $(250 \mu \mathrm{Ci})$ of ${ }^{113} \mathrm{In}^{\mathrm{m}}$, two cheese sandwiches and a cup of tea. Details of the test meal characteristics, isotope labelling technique and stability of the ${ }^{113} \mathrm{In}^{\mathrm{m}}$ have been published elsewhere. ${ }^{7}$ After 60 minutes incubation in hydrochloric acid between $\mathrm{pH} 3 \cdot 3$ and $5 \cdot 0$, no more than $7 \%$ of the label detached. In gastric juice at $\mathrm{pH} 2 \cdot 01$, only $5 \cdot 6 \%$ of the label was removed after 30 minute incubation.

Data were then acquired simultaneously from the ${ }^{113} \mathrm{In}^{\mathrm{m}}$ gastric content tracer and the ${ }^{4 \%} \mathrm{Tc}^{\mathrm{m}}$ gall bladder bile tracer at the rate of one frame per minute. All data were stored on a hard magnetic disk for subsequent analysis.

DATA ANALYSIS

For analysis, regions of interest were drawn around the gall bladder, stomach, composite of liver and gall bladder, liver adjacent to gall bladder for overlap subtraction, small intestine and background. From the time activity curves constructed by the computer, gastric and gall bladder filling and emptying curves were generated (Fig. 1).

Gastric emptying was expressed either as a single $t_{1 / 2}$ when the function was monoexponential (computer least squares fit program) or as two $t_{1 / 2} s$ when the function was double exponential (computer program using Prony's method. ${ }^{4}$

Gall bladder emptying was expressed as a double exponential function (where possible) with appropriate $t_{1 / 2} s$ and as an ejection fraction over a specified time interval - that is, the percentage reduction in gall bladder area counts over a specified period.' Gall bladder partitioning (the fraction of amount of biliary tracer, taken up by the liver, that enters the gall bladder) was determined by dividing the maximum gall bladder count by the maximum count obtained in the composite liver and gall bladder region of interest (expressed as a percentage).

All isotope counts were corrected for decay. The times from the start of meal ingestion until gastric and gall bladder emptying started were recorded.

Results are expressed as mean \pm SEM unless otherwise stated. A non-parametric Mann-Whitney U-test and Wilcoxon's matched pairs test were used to test for significance. Multiple comparisons were made using analysis of variance and Student-NuemanKuells test.

\section{REPRODUCIBILITY}

Reproducibility, intraobserver and interobserver errors of the dual-isotope test in normal subjects are reported elsewhere. ' In the present study, three patients underwent reproducibility studies.

\section{Results}

\section{GASTRIC EMPTYING}

Patients after a TV $+\mathrm{P}$ or HSV took significantly longer than unoperated patients to eat the test meal (Table 1). In all patients, however, gastric emptying started at approximately the same time after beginning the meal (Table 1).

The pattern of gastric emptying was monoexponential $\left(t_{1 / 2}=48 \cdot 3 \pm 4 \cdot 1 \mathrm{~min}\right)$ in most patients $(23$ of 27) with a duodenal ulcer before operation. The remaining four patients exhibited a double exponential pattern before $\left(t_{1 / 2}\right.$ first $\exp =7 \cdot 3 \pm 1 \cdot 3 \mathrm{~min} ; t_{1 / 2}$ second $\exp =179.0 \pm 58.9 \mathrm{~min})$ and after $t_{1 / 2}$ first $\exp =5 \cdot 9 \pm 1 \cdot 7 \mathrm{~min} ; t_{1 / 2}$ second $\exp =152 \cdot 6 \pm 20 \cdot 0 \mathrm{~min}$ ) operation.

In the majority of patients after TV $+P(29$ of 34$)$, the gastric emptying pattern was double exponential $\left(t_{1 / 2}\right.$ first $\exp =5 \cdot 6 \pm 0.4$ min; $t_{1 / 2}$ second exp= $141 \cdot 4 \pm 17.4 \mathrm{~min}$ ); an example is shown in Figure 1. In the remaining six patients after $\mathrm{TV}+\mathrm{P}$ the gastric 

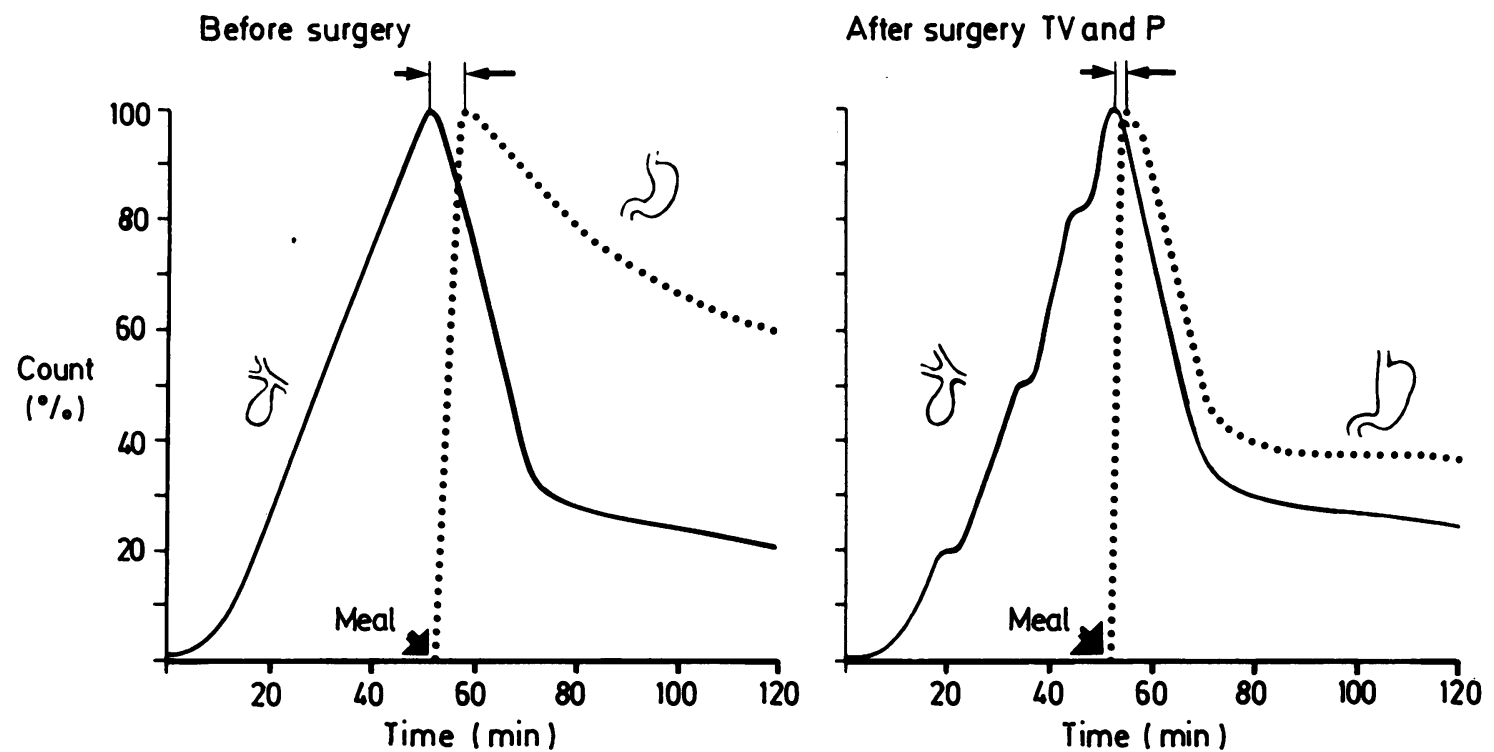

Fig. 1 Relationship between gastric emptying and gall bladder emptying in a patient with a duodenal ulcer, before (left) and after (right) $T V+P$. The solid line denotes gall bladder filling and emptying and the dotted line gastric filling and emptying. Note: (i) the early onset of gall bladder emptying before onset of gastric emptying (arrows) which is reduced after surgery, (ii) the conversion of a monoexponential gastric emptying pattern before operation to a double exponential pattern after surgery, and (iii) the uniform filling of the gall bladder before operation and the stepwise filling of the gall bladder after operation.

emptying pattern was monoexponential $\left(t_{1 / 2}=\right.$ $47 \cdot 4 \pm 7 \cdot 0 \mathrm{~min})$.

In contrast, most patients after a HSV (13 of 15) had a monoexponential pattern of gastric emptying $\left(t_{1 / 2}=47 \cdot 7 \pm 4.3 \mathrm{~min}\right)$. The two remaining patients with a HSV had double exponential gastric emptying patterns. Thus, HSV did not alter preoperative gastric emptying patterns in most patients but $\mathrm{TV}+\mathrm{P}$ resulted in most patients in a double exponential pattern with much more rapid gastric emptying.

\section{GALL BLADDER FILLING}

In those patients who did not exhibit spontaneous gall bladder emptying (see next section) the gall bladder filled in one of two ways - that is, uniform or

Table 1 Comparison of times to ingest meal and onset of gastric emptying in all study groups

\begin{tabular}{llll}
\hline & $\begin{array}{l}\text { Duodenal ulcer } \\
(n=27)\end{array}$ & $\begin{array}{l}T V+P \\
(n=35)\end{array}$ & $\begin{array}{l}H S V \\
(n=17)\end{array}$ \\
\hline $\begin{array}{c}\text { Time to ingest meal } \\
\text { (min) }\end{array}$ & $7 \cdot 9 \pm 0 \cdot 4$ & $9 \cdot 9 \pm 0 \cdot 3^{*}$ & $9 \cdot 5 \pm 0 \cdot 6 \dagger$ \\
$\begin{array}{c}\text { Onset of gastric } \\
\text { cmptying (min) }\end{array}$ & $6 \cdot 3 \pm 0 \cdot 4$ & $6 \cdot 6 \pm 0 \cdot 4$ & $7 \cdot 4 \pm 0 \cdot 6$ \\
\hline
\end{tabular}

Onset of gastric emptying measured from start of meal ingestion: ${ }^{*} p<0.001$ (compared with DU patients); $\uparrow p<0.02$ (compared with DU patients). stepwise (Fig. 1). The 'steps' in the filling curve corresponded to the appearance of the bile tracer in the small intestine when no gall bladder filling or emptying was occurring; thus, the hepatic bile was bypassing the gall bladder and emptying directly into the duodenum. There were no significant differences in the proportion of uniform (U) or stepwise (S) filling patterns in any of the study groups (duodenal ulcer $\mathrm{U}: \mathrm{S}=9: 14, \mathrm{TV}+\mathrm{P} \mathrm{U}: \mathrm{S}=19: 12$, HSV U:S=7:6). More tracer entered the gall bladder (gall bladder partitioning) in patients who filled uniformly $(74 \cdot 0 \pm 1 \cdot 8 \%)$ compared with those patients who filled in a stepwise manner $(50.5 \pm 4 \cdot 1 \%, p<0 \cdot 001)$.

Reproducibility studies showed that patterns of gall bladder filling were not consistent (see below). In two patients, uniform filling was observed in initial studies and repeat studies. In the remaining patient, however, stepwise filling was observed initially but he filled uniformly during the repeat study. Moreover, the pattern of gall bladder filling was often altered after operation: some patients filled their gall bladder in a uniform pattern before surgery then filled stepwise after surgery, and vice versa.

In those patients who exhibited uniform filling patterns there were no significant differences in filling rates between the study groups; duodenal ulcer= $2.7 \pm 0.2 \%$ min, $\mathrm{TV}+\mathrm{P}=2 \cdot 1 \pm 0 \cdot 1 \% / \mathrm{min}, \mathrm{HSV}=$ $2 \cdot 4 \pm 0 \cdot 2 \% / \mathrm{min}$. 


\section{GALL BLADDER EMPTYING}

In some patients the gall bladder began to empty spontaneously while the count rate in the gall bladder region of interest was rising to a plateau before the meal was taken. These patients could not be evaluated and are not considered further. In the majority of patients, however, the gall bladder began to empty during or after the meal. Thus, 23 of 27 patients with a duodenal ulcer who were prospectively studied before and after operation came into this category $(\mathrm{TV}+\mathrm{P}, \mathrm{n}=13 ; \mathrm{HSV}, \mathrm{n}=10)$. Also in the 25 patients studied only after operation, 21 were emptied in relation to a meal $(\mathrm{TV}+\mathrm{P}, \mathrm{n}=18 ; \mathrm{HSV}, \mathrm{n}=3)$.

The gall bladder began to empty $2 \cdot 7 \pm 0 \cdot 8 \mathrm{~min}$ after the beginning of the meal in patients with a duodenal ulcer, $6 \cdot 2 \pm 0.8 \mathrm{~min}$ in the patients after $\mathrm{TV}+\mathrm{P}$, and $2.5 \pm 1.0 \mathrm{~min}$ in patients after $\mathrm{HSV}$ (Fig. 2). The delay in onset of gall bladder emptying after $\mathrm{TV}+\mathrm{P}$ was significantly greater than in patients with a duodenal ulcer or after HSV (Fig. 2).

\section{PATTERN OF GALL BLADDER EMPTYING}

Previous studies in normal subjects ${ }^{7}$ have shown that there are two distinct patterns of gall bladder emptying after meal ingestion; type I (fast and near complete gall bladder emptying) and type II (slow with less gall bladder emptying). We found in the present study that in all but one of the patients with a duodenal ulcer or HSV, the patterns of gall bladder emptying were similar - that is, Type I and Type II, to those previously described for normal subjects (Fig. 3). This subdivision into two types is characterised by two parameters - that is $t_{1 / 2}$ (first exp) of the gall bladder emptying curve, and gall bladder ejection

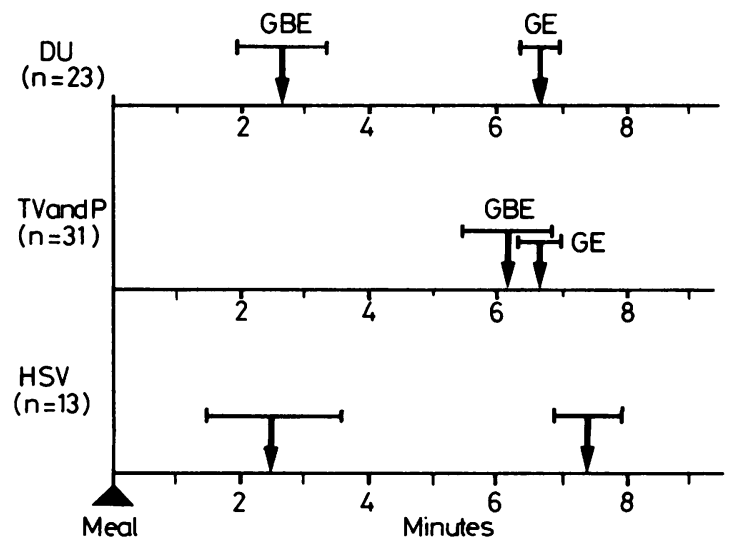

Onset of GBE, TV and P v DU $p<0.001$

TV and $\mathrm{P} \vee \mathrm{HSV} p<0.005$

Fig. 2 Times of onset of gastric and gall bladder emptying (measured from the beginning of meal ingestion). Results expressed as mean $\pm S E M$. Delay in onset of gall bladder emptying after $T V+P$ can be observed.

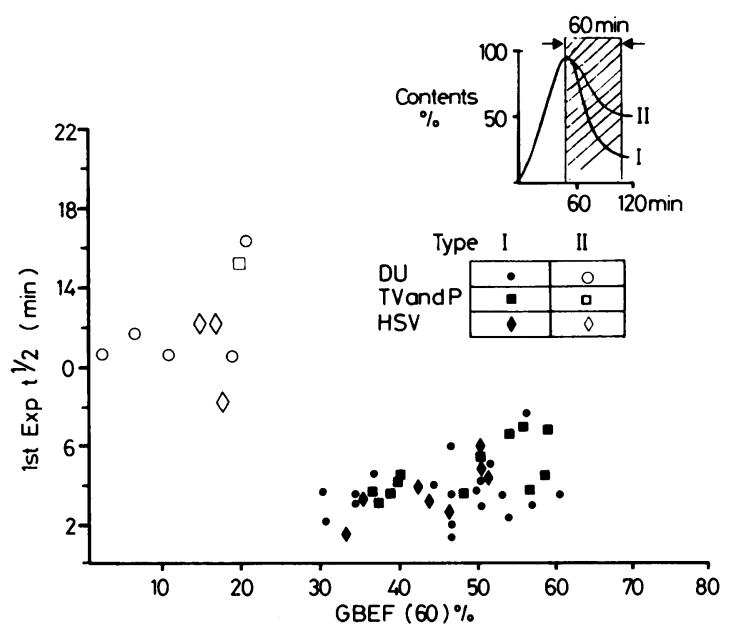

Fig. 3 Division of patterns of gall bladder emptying into type I and II patterns. The inset shows how this division was made on the basis of two parameters; for each gall bladder emptying curve the $t_{1 / 2}$ of the first exponential was calculated and the amount of gall bladder contents emptied during the first 60 minutes of gall bladder emptying (GBEF 60), shaded area.

fraction over the first $60 \mathrm{~min}$ of gall bladder emptying and allows clear separation of the two types (Fig. 3).

Patients who exhibited a type I gall bladder emptying pattern (duodenal ulcer $n=18 ; T V+P, n=12$; HSV , $n=9$ ) had rapid gall bladder emptying (mean $t_{1 / 2}$ (first exp) of $4.9 \pm 0.7 \mathrm{~min}$ ) and emptied a greater proportion of gall bladder contents in a specified period (mean 60 min ejection fraction of 75.6士 $1.4 \%)$. In patients with a type II pattern of gall bladder emptying (duodenal ulcer, $n=5 ; T V+P$, $\mathrm{n}=1 ; \mathrm{HSV}, \mathrm{n}=3$ ), emptying of the gall bladder was slower (mean $t_{1 / 2}$ (first exp) of $15 \cdot 3 \pm 1 \cdot 1 \mathrm{~min}$ ) and thus less complete (mean 60 minute ejection fraction of $43 \cdot 4 \pm 2 \cdot 0 \%$ ).

All patients with a duodenal ulcer had either a type I $(n=18)$ or type II $(n=5)$ pattern of gall bladder emptying. In the 31 patients with a $\mathrm{TV}+\mathrm{P}$, however, there were 12 type I patterns and only 1 type II pattern (Fig. 3). The remaining 18 patients with a $\mathrm{TV}+\mathrm{P}$ exhibited two additional patterns of gall bladder emptying which had not been observed in duodenal ulcer patients or our previous studies in 22 normal volunteers.' These two additional gall bladder emptying patterns were called type III and type IV patterns (Fig. 4). The incidence of these patterns was independent of the timing of previous surgery. Patients with a type III gall bladder emptying pattern commenced gall bladder emptying similar to a patient with a type I gall bladder emptying pattern but after completion of the rapid emptying phase one of two things happened: in one subgroup 

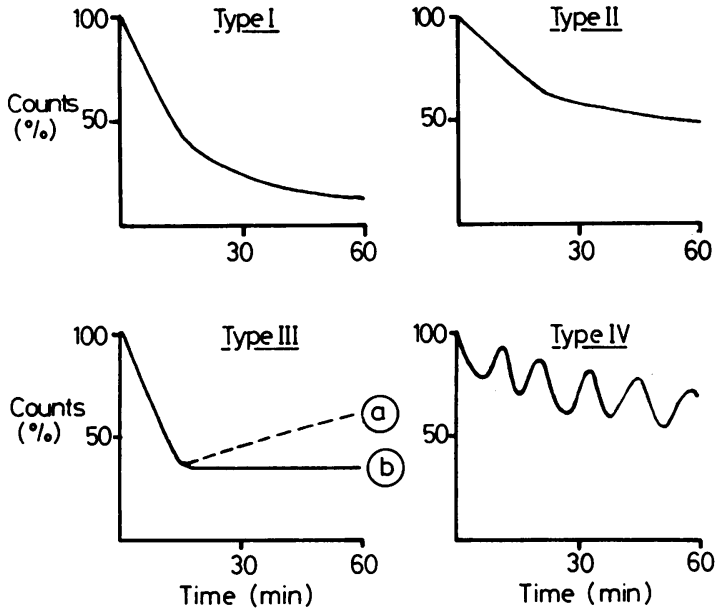

Fig. 4 Gall bladder emptying patterns observed. Patients with a duodenal ulcer exhibited type I and II patterns only, whilst patients with a $T V+P$ exhibited type I, II, III, and IV patterns. Patients with a HSV exhibited type I, II, and IV patterns. For description of patterns see text.

(type IIIa, $n=5$; Fig. 4) the gall bladder refilled during the remainder of the study; in the other subgroup (type IIIb, $n=7$; Fig .4) the gall bladder neither filled nor emptied during the remainder of the study. Patients after a TV $+P$ in whom a type IV gall bladder emptying pattern was observed $(n=6)$ had irregular gall bladder emptying with alternating filling and emptying (Fig. 4).

In patients with a HSV there were nine type I and three type II gall bladder emptying patterns observed. The remaining patient with a HSV had a type IV gall bladder emptying pattern.

QUANTITATIVE RELATIONSHIP BETWEEN GASTRIC AND GALL BLADDER EMPTYING

In patients with a duodenal ulcer or after HSV, the gall bladder always began to empty before the stomach did (Fig. 2), emptying $9.6 \pm 1.7 \%$ and $11.9 \pm 1.3 \%$ respectively of its contents into the duodenum before the onset of gastric emptying (Fig. 5). After a TV $+P$, however, patients only emptied $2 \cdot 4 \pm 1.0 \%$ of gall bladder contents into the duodenum before the onset of gastric emptying (Fig. 5).

The pattern of gall bladder emptying was not consistently related to the pattern of gastric emptying - the rate of emptying of one organ seemed independent of the other. If all patients with a consistent gall bladder emptying pattern (type I) are further examined, there was no correlation between the proportion of gall bladder and gastric contents emptied during the first 15 minutes (arbitrarily chosen interval) of gastric emptying (Fig. 6). Thus, even in a small time interval after the onset of gastric

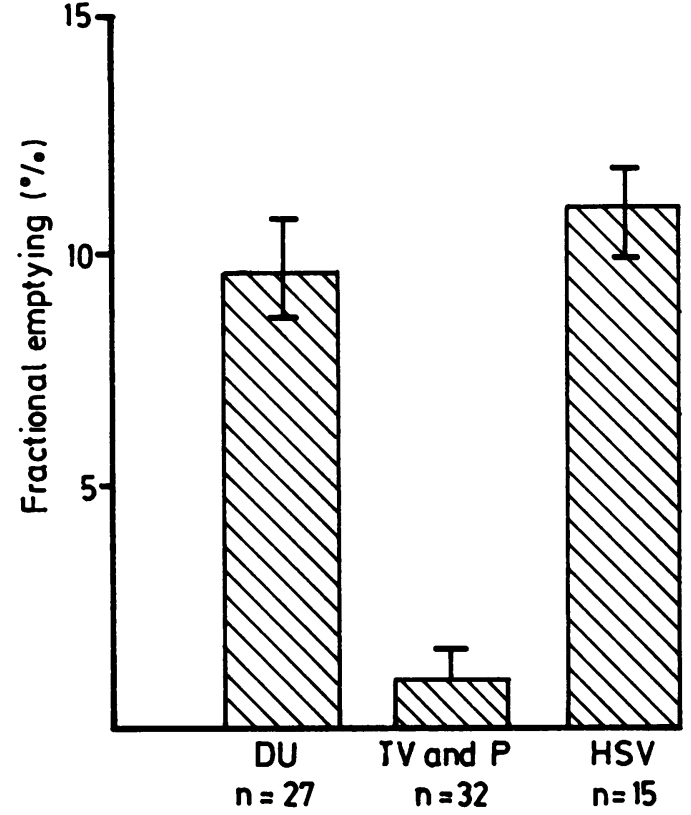

Fig. 5 Proportion of gall bladder contents emptied into the duodenum before the onset of gastric emptying. Patients with $T V+P$ emptied significantly less gall bladder contents into the duodenum $(p<0.001)$ compared with patients with a duodenal ulcer or patients with a HSV.

emptying, there is no relationship between the rate of emptying of either organ. Furthermore, the contents of the gall bladder that entered the small intestine during the first 15 minutes of gastric emptying were mixed with a greater volume of gastric contents in patients with a TV $+P$ with type I gall bladder emptying patterns than in patients with a duodenal ulcer or HSV with the same gall bladder emptying pattern $(p<0.001$, Fig. 7). This was clearly because of mistiming of emptying gastric and gall bladder contents as there was a larger amount of gastric contents emptied during the first 15 minutes of gastric emptying after $a T V+P$.

In patients with a type III gall bladder emptying pattern after $\mathrm{TV}+\mathrm{P}$, gall bladder emptying during the first 15 minutes of gastric emptying was similar to a type I gall bladder emptying pattern (Fig. 4). Thereafter, however, the relationship between gastric emptying and gall bladder emptying was quite different from a type I or II gall bladder emptying pattern. In the type IIIa gall bladder emptying pattern, there was no gall bladder or hepatic bile to mix with gastric contents emptying later as the gall bladder continued to fill for the remainder of the study. In patients with a type IIIb gall bladder emptying pattern bile did not mix with later emptying gastric contents, because the gall bladder emptying 


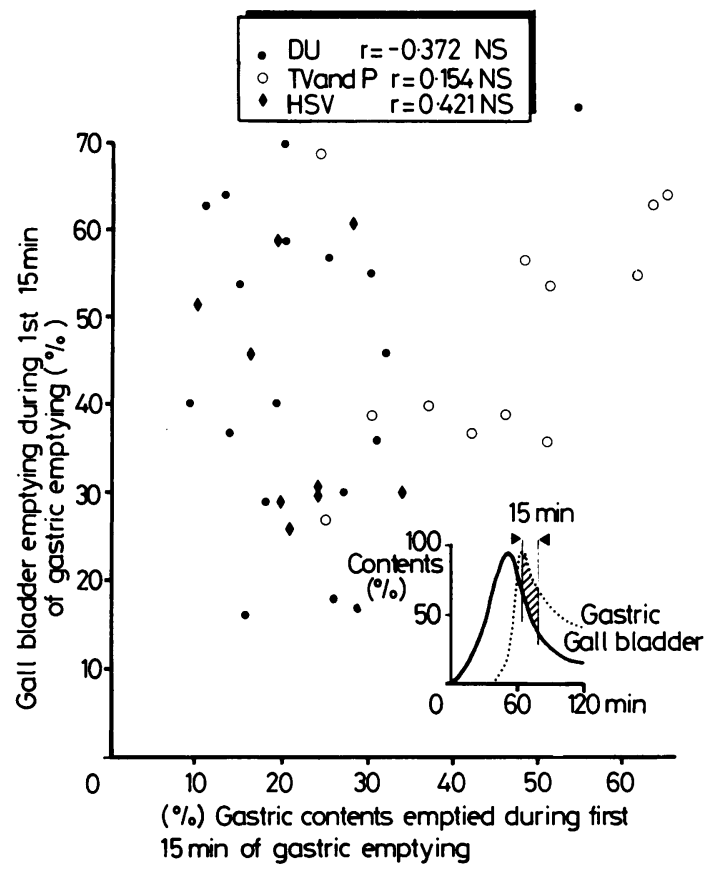

Fig. 6 Relationship between amount of contents emptied from stomach and gall bladder during the first 15 minutes after onset of gastric emptying in patients and a type I gall bladder emptying pattern. The inset shows the time interval during which these measurements were made. There was no relationship between the amount of gastric and gall bladder contents emptied during this time interval.

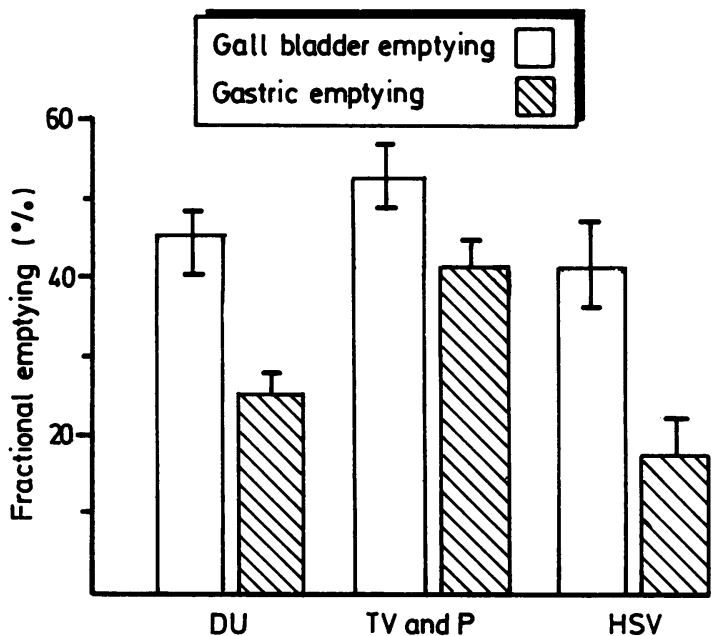

Fig. 7 Percentage of gall bladder and gastric contents emptied during the first 15 minutes after onset of gastric emptying in patients with type I gall bladder emptying patterns. Significantly more gastric contents were emptied after $T V+P$ when compared with patients with duodenal ulcer or patients with a HSV $(p<0 \cdot 001)$. curve was horizontal during this part of the study. These patients, however, were emptying hepatic bile into the small intestine to mix with emptying gastric contents during the later part of the study.

In patients with a type IV gall bladder emptying pattern, emptying gastric contents were only intermittently mixed with gall bladder or hepatic bile because of the periodic nature of gall bladder emptying in these patients.

Of the 13 patients studied before and after a $T V+P$, nine had altered gall bladder emptying patterns after operation, but in the remaining four, the pattern of gall bladder emptying (type I) was unchanged (Fig. 8, Table 2). In contrast, in 10 of the patients who underwent HSV, the gall bladder emptying patterns were not altered by surgery (Fig. 8 , Table 3). Thus, the patterns of gall bladder emptying were significantly more likely to be altered by TV+P when compared with HSV $(p<0.002)$ (Fig. 8).

\section{REPRODUCIBI LITY}

Reproducibility studies were carried out in three patients who had undergone a TV $+P$. One patient had a type I gall bladder emptying during both studies (first study $-t_{1 / 2}$ first exp $=3 \cdot 2$ min, $t_{1 / 2}$ second exp $=91$ $\min$ and GBEF $(10)=37 \%$; second study $=t_{1 / 2}$ first $\exp =4.1 \mathrm{~min}, \mathrm{t}_{1 / 2}$ second $\exp =110 \mathrm{~min}$ and GBEF $(10)=31 \%$. In the remaining two patients, one had a type III gall bladder emptying pattern in both studies and the other patient exhibited a type IV gall bladder emptying pattern during both studies (Fig. 9). Thus, in all three instances, the gall bladder emptying patterns observed were consistently reproducible.

\section{Discussion}

It has been generally assumed that gall bladder emptying is stimulated by the release from the small intestine of peptide hormones, in particular, cholecystokinin. Our previous studies, however,

Table 2 Gall bladder emptying parameters in the four patients with DU who had type I gall bladder emptying patterns before and after surgery $(T V+P)$

\begin{tabular}{|c|c|c|c|c|c|c|}
\hline \multirow[b]{2}{*}{ Patient } & \multicolumn{3}{|c|}{ Before surgery } & \multicolumn{3}{|c|}{ After $T V+P$} \\
\hline & $\begin{array}{l}\text { lstexp } \\
t_{1 / 2} \\
(\text { min })\end{array}$ & $\begin{array}{l}\text { 2nd exp } \\
t_{1 / 2} \\
(\mathrm{~min})\end{array}$ & $\begin{array}{l}G B E F \\
(10 \text { min }) \\
(\%)\end{array}$ & $\begin{array}{l}\text { Ist exp } \\
t_{1 / 2} \\
(\text { min })\end{array}$ & $\begin{array}{l}2 n d \exp \\
t_{1 / 2} \\
(\mathrm{~min})\end{array}$ & $\begin{array}{l}G B E F \\
(10 \min ) \\
(\%)\end{array}$ \\
\hline (a) & $7 \cdot 0$ & 88 & 27 & $6 \cdot 4$ & 99 & 30 \\
\hline (b) & $5 \cdot 5$ & 100 & 44 & $6 \cdot 1$ & 108 & 36 \\
\hline (c) & $6 \cdot 3$ & 110 & 39 & $5 \cdot 6$ & 50 & 47 \\
\hline (d) & 3.6 & 76 & 60 & $4 \cdot 8$ & 87 & 50 \\
\hline
\end{tabular}

Paired Student's $t$ test: 1 st $\exp t_{1 / 2}=0 \cdot 2691$, NS: 2 nd $\exp t_{1 / 2}=0 \cdot 000$. NS; $\operatorname{GBEF}(10)=0 \cdot 4044$, NS. 
Table 3 Gall bladder emptying parameters before and after surgery in the 10 patients with a duodenal ulcer who received a HSV

\begin{tabular}{|c|c|c|c|c|c|c|}
\hline \multirow[b]{2}{*}{$\begin{array}{l}\text { Patients } \\
\text { and pattern } \\
\text { before } \\
\text { surgery }\end{array}$} & \multicolumn{3}{|c|}{ Before surgery } & \multicolumn{3}{|c|}{ After surgery } \\
\hline & $\begin{array}{l}\text { Istexp } \\
t_{I_{/ 2}} \\
(\text { min })\end{array}$ & $\begin{array}{l}2 n d \exp \\
t_{I_{2}} \\
(\min )\end{array}$ & $\begin{array}{l}G B E F \\
(60)(\%)\end{array}$ & $\begin{array}{l}\text { lstexp } \\
t_{I_{/ 2}} \\
(\text { min })\end{array}$ & $\begin{array}{l}2 n d \exp \\
t_{I_{/ 2}} \\
(\min )\end{array}$ & $\begin{array}{l}G B E F \\
(60)(\%)\end{array}$ \\
\hline (e) (I) & $3 \cdot 5$ & 75 & 79 & $3 \cdot 2$ & 66 & 78 \\
\hline (f) (I) & $5 \cdot 1$ & 80 & 85 & $5 \cdot 5$ & 48 & 81 \\
\hline (g) (i) & $8 \cdot 0$ & 95 & 68 & $9 \cdot 0$ & 72 & 74 \\
\hline (h) (I) & $4 \cdot 2$ & 200 & 72 & $3 \cdot 2$ & 201 & 65 \\
\hline (i) (I) & $4 \cdot 6$ & 121 & 68 & 40 & 146 & 59 \\
\hline (j) (I) & $3 \cdot 2$ & 144 & 74 & $4 \cdot 7$ & 157 & 71 \\
\hline (k) (I) & $2 \cdot 0$ & 49 & 81 & $1 \cdot 5$ & 55 & 83 \\
\hline (I) (I) & $7 \cdot 6$ & 162 & 76 & $6 \cdot 0$ & 180 & 75 \\
\hline (m) (II) & $15 \cdot 9$ & 246 & 40 & $17 \cdot 0$ & 271 & 46 \\
\hline (n) (II) & $16 \cdot 3$ & 251 & 43 & $15 \cdot 5$ & 249 & 38 \\
\hline
\end{tabular}

Wilcoxon's matched pairs: 1 st $\operatorname{exp~t}_{1 / 2} \mathrm{~T}=26, \mathrm{NS} ; 2$ nd exp $t_{1 / 2} T=14, N S ; \operatorname{GBEF}(60) T=17, N S$.

suggested the existence of 'preduodenal' mechanisms because the gall bladder began to empty before the stomach. ${ }^{7}$ The present study confirms these previous observations now in patients with a duodenal ulcer or patients after a HSV. After a TV $+P$, however, the onset of gall bladder emptying is delayed (Fig. 2). This observation suggests that a long vagal pathway mediating the preduodenal mechanisms may be involved in the initiation of gall bladder emptying. The precise nature of the preduodenal mechanisms is unclear. The relatively rapid onset of gall bladder emptying after a meal in patients with duodenal ulcer and patients with a HSV suggests that there is a cephalic phase, probably neural, rather than a gastric phase for the initiation of gall bladder emptying, which is often well advanced before there is much food in the stomach. A vagally mediated gastric phase for gall bladder emptying has been shown in dogs $^{10}$ but this has not yet been confirmed in man. Further studies are clearly necessary to determine the precise nature of the controlling 'preduodenal' mechanisms responsible for gall bladder emptying.

\begin{tabular}{|c|c|c|c|}
\hline & & Altered & Not altered \\
\hline $\begin{array}{l}T V+P \\
(n=13)\end{array}$ & $\begin{array}{l}\text { Before } \\
\text { surgery } \\
\text { Atter } \\
\text { surgery }\end{array}$ & III $\overbrace{(4)}^{I(6)} \overbrace{9}^{I I}(2) \overbrace{I V(2)}$ & $\begin{array}{l}1(4) \\
b \\
1(4) \\
4\end{array}$ \\
\hline $\begin{array}{l}\text { HSV } \\
(n=10)\end{array}$ & $\begin{array}{l}\text { Betore } \\
\text { surgery } \\
\text { Atter } \\
\text { surgery }\end{array}$ & 0 & 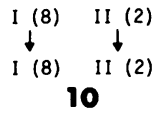 \\
\hline
\end{tabular}

$P=0.002$ Fishers exact test

Fig. 8 Gall bladder emptying patterns before and after surgery in the 23 patients who had satisfactory preoperative and postoperative studies.
The patterns of gall bladder emptying in all patients with a duodenal ulcer and all but one patient with a HSV were similar to those previously reported in normal subjects - that is, either a rapid, large ejection pattern (type I) or, a slow, small ejection pattern (type II). After TV+P, however, in approximately $60 \%$ of patients the patterns of gall bladder emptying are greatly altered. In the very limited reproducibility studies done these were consistent. Furthermore, these altered patterns of gall bladder emptying were not related to the pattern of gastric emptying observed or the timing of previous surgery.

In all but one of the patients studied with a HSV, the patterns of gall bladder emptying were similar to those observed in unoperated duodenal ulcer patients - that is, type I or type II patterns. In particular, in the 10 patients who received a HSV who were studied before and after surgery, the pattern of gall bladder emptying after surgery was the same as that observed before surgery.

Therefore, this study shows that $\mathrm{TV}+\mathrm{P}$ may disorganise gall bladder emptying patterns and HSV generally preserves them. Furthermore, the rapid initial gastric emptying observed after $\mathrm{TV}+\mathrm{P}$ indicates mismatch between the emptying of the stomach and the gall bladder. Thus, TV $+\mathrm{P}$ produces considerable mistiming of emptying gastric and gall bladder contents because of three mechanisms; (i) delay in onset of gall bladder emptying (all patients), (ii) altered gall bladder emptying patterns (60\% of patients), and (iii) rapid initial gastric emptying ( $85 \%$ of patients). This study also suggest that the rate of gastric emptying is a relatively

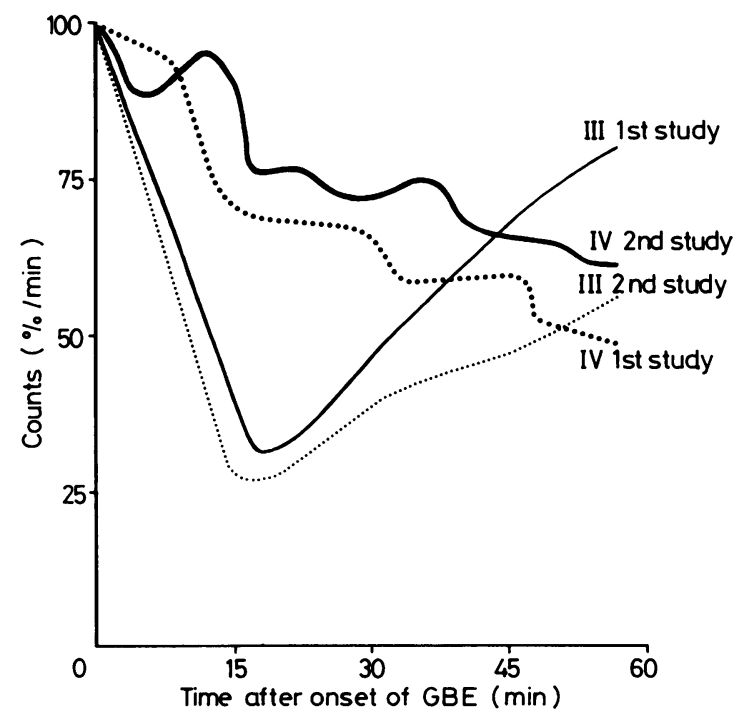

Fig. 9 Reproducibility studies in two patients who have previously received a $T V+P$. 
unimportant factor in determining the pattern and rate of gall bladder emptying.

It is not clear why some patients after TV+P maintain normal gall bladder emptying patterns that is, type I and II patterns, whilst in others, the gall bladder emptying pattern is altered. As completeness of vagotomy was not tested in any of the TV+P patients studied there is the possibility that the variation in the postoperative gall bladder emptying patterns could be related to completeness, or otherwise, of vagotomy. This explanation is unlikely for two reasons; (i) all patients were asymptomatic, many for as long as 20 years after vagotomy, and (ii) in all cases the operation notes revealed at least two histologically proven vagal trunks; the nerves which are missed are usually branches to the fundus of the stomach rather than the hepatic plexus.

The type IIIb and IV gall bladder emptying patterns observed after a $\mathrm{TV}+\mathrm{P}$ suggest that some incoordination may exist between the gall bladder and the sphincter of Oddi. Because these patterns were only consistently observed after a truncal vagotomy only, it is likely that the neurectomy is an important cause of the incoordination. Thus, intact vagal innervation to the gall bladder and sphincter of Oddi may be necessary to coordinate gastric emptying and gall bladder emptying. Hitherto, the autonomic supply to the biliary apparatus has been considered of minor importance in the control of gall bladder emptying. ${ }^{9}$ The one type IV gall bladder emptying pattern observed one patient after HSV may conceivably have resulted from an inadvertent truncal vagotomy.

It is known from the investigations of Fields and Duthie $^{12}$ and Edwards $e t a^{8}$ that patients with a $\mathrm{TV}+\mathrm{P}$ have abnormalities in fat digestion and absorption. Although the reasons for these abnormalities are several - that is, reduced pancreatic lipase secretion, ${ }^{13}{ }^{14}$ rapid gastric emptying with dilution of upper gastrointestinal secretions,${ }^{14}$ incoordination between gall bladder emptying and gastric emptying may also be contributory. This study shows that after HSV the motility of the upper gastrointestinal tract is less disturbed than after TV $+\mathrm{P}-$ gastric emptying of solids is less regularly altered and the temporal and quantitative relationships between gastric emptying and gall bladder emptying are usually unaltered. Moreover, it is also known that $\mathrm{HSV}$, unlike TV $+\mathrm{P}$ does not reduce the secretion of pancreatic lipase. ${ }^{15}$ Indeed, there is some evidence to indicate that fat malabsorption is less common after HSV than TV $+P .{ }^{8}$ Thus, fat digestion and absorption are less affected by HSV than TV $+P$ and that maintenance of the normal relationship between gastric emptying and gall bladder emptying may be contributory towards this.
Most investigators studying the effect of vagotomy on gall bladder motility have used exogenous cholecystokinin ${ }^{16} 17$ as the stimulus for gall bladder emptying. Investigations of this kind, ignore preduodenal mechanisms, and would not, therefore, be expected fully to delineate the precise gall bladder emptying pattern in these patients.

The spontaneous emptying of the gall bladder observed before the meal was given to the patients was also observed in normal subjects. ' Spontaneous emptying is said to be initiated by the late phase 2 of the interdigestive migrating motor complex (IMMC), and has been observed in the $\operatorname{dog}^{18}$ and man. ${ }^{19}$ There was a tendency for this spontaneous emptying to be less common after $\mathrm{TV}+\mathrm{P}$ than in patients with a duodenal ulcer. As it is known that truncal vagotomy interferes with the cycling and frequency of the IMMC cycle in the variable manner, ${ }^{20}$ this may partly account for the reduction in spontaneous emptying observed in patients after $\mathrm{TV}+\mathrm{P}$.

Gall bladder filling patterns (uniform and stepwise) did not appear to be influenced by vagotomy of either type. Limited reproducibility studies, however, have suggested that filling patterns are variable and that both patterns may be seen in the same patient on different occasions. In those subjects with uniform filling patterns, the filling rates were similar to those we previously reported for normal subjects ${ }^{7}$ and to those observed by other investigators. ${ }^{21}$

The patterns of gastric emptying after operation were similar to those reported by other workers for solid meals. ${ }^{122}$ Thus, after TV $+\mathrm{P}$ the stomach empties in a double exponential pattern with a very fast first exponential and a much slower second exponential. In contrast, the preoperative pattern of gastric emptying observed is not changed by a HSV. In the patients with a duodenal ulcer before operation, the patterns of gastric emptying observed were also similar to those reported by other investigators: most patients have normal gastric emptying patterns but there is a small subgroup of patients with faster initial gastric emptying - that is, a double exponential pattern. ${ }^{23}$

Interestingly, the time taken for onset of gastric emptying after the start of the meal was not different in any of the study group - that is, patients with a duodenal ulcer, TV +P or HSV. If the times of onset of gastric emptying in these study groups are compared with those obtained for a large group of normal healthy subjects, however (unpublished data), it was found that normal subjects began gastric emptying significantly later than any of the patients in the present study $(p<0.001)$ (Fig. 10). Stated in another way, unoperated patients with a duodenal ulcer commenced gastric emptying faster than normal 


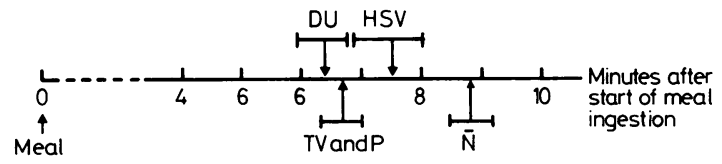

Fig. 10 Comparison of times for onset of gastric emptying in all study groups compared with a group of normal subjects (N) $(n=22)$. Normal subjects commenced gastric emptying significantly later than patients with a duodenal ulcer or $T V+P(p<0.001)$ or HSV $(p<0.02)$.

controls and this remained unchanged after either a $\mathrm{TV}+\mathrm{P}$ or a HSV. This observation which has not been previously reported adds yet another abnormality in gastric function to the many which have already been reported in duodenal ulcer patients.

In summary, we have shown that $\mathrm{TV}+\mathrm{P}$, but not HSV, often disturbs the pattern of gall bladder emptying. Furthermore, TV+P, but not HSV, delays the onset of gall bladder emptying but neither operation affects the onset of gastric emptying after the meal. The net effects of these changes is that the coordination of gastric emptying and gall bladder emptying is altered in many patients following a $\mathrm{TV}+\mathrm{P}$ but not following an HSV. When considered in conjunction with other reported observations on upper gastrointestinal function after operation, these results suggest that $\mathrm{HSV}$ is more likely to maintain near normal coordination of motilty and secretory activity of the gall bladder and stomach than TV $+P$.

This investigation was supported by a research grant from the Mersey Regional Health Authority, England. Part of this work has been presented to the British Society of Gastroenterology, York 1983 and Manchester 1984.

\section{References}

1 MacGregor IL, Martin MS, Meyer JH. Gastric emptying of solid food in normal man and after subtotal gastrectomy and truncal vagotomy and drainage. Gastroeneterology 1977; 72: 206-11.

2 Sheiner HJ. Gastric motility and emptying in normal and post-vagotomy subjects. Gut 1980; 21: 753-9.

3 Minami H, McCallum RW. The physiology and pathophysiology of gastric emptying in humans. Gastroenterology 1984; 86: 1592-610.

4 Rudrick J, Hutchison JSF. Effects of vagal-nerve section on the biliary system. Lancet 1964; i: 579-81.

5 Cox HT, Doherty JF, Kerr DF. Changes in the gallbladder after elective gastric surgery. Lancet 1958; i: 764-6.
6 Glanville JN, Duthie HL. Contraction of the gallbladder before and after total abdominal vagotomy. Clin Radiol 1964; 15: 350-4.

7 Baxter JN, Grime JS, Critchley M, et al. Relationship between gastric emptying of solids and gall bladder emptying in normal subjects. Gut 1985; 26: 342-51.

8 Edwards JP, Lyndon PJ, Smith RB, et al. Faecal fat excretion after truncal selective, and highly selective vagotomy for duodenal ulcer. Gut 1974; 15: 521-5.

9 Hildebrand FB. Introduction to numerical analysis. New York: McGraw-Hill Book Co, 1956.

10 Debas HT, Yamagishi T. Evidence for a pylorocholecystic reflex for gallbladder contraction. Ann Surg 1979; 190: 170-5.

11 Soloway RD, Balistreri WF, Trotman BW. The gallbladder and the biliary tract. In: Bouchier AD, ed. Recent advances in gastroenterology 4. New York: Churchill Livingstone, 1980: 259.

12 Fields M, Duthie HL. Effects of vagotomy on intraluminal digestion of fat in man. Gut 1960; 6: 301-10.

13 Malagelada JR, Go VLW, Summerskill WHJ. Altered pancreatic and biliary function after vagotomy and pyloroplasty. Gastroenterology 1974; 66: 22-7.

14 MacGregor IL, Parent J, Meyer JH. Gastric emptying of liquid meals and pancreatic and biliary secretion after subtotal gastrectomy or truncal vagotomy and pyloroplasty in man. Gastroenterology. 1977; 72: 195-205.

15 Ramus NI, Williamson RCN, Johnston D. Effect of highly selective vagotomy on pancreatic exocrine function and on cholecystokinin and gastrin release. Gut 1982; 23: 553-7.

16 Shaffer EA. The effect of vagotomy on gallbladder function and bile composition in man. Ann Surg 1982; 195: 413-8.

17 Pellegrini CA, Lewin M, Patti MG, et al. Gallbladder filling and response to cholecystokinin are not affected by vagotomy. Surgery $1985 ; 98: 452-7$.

18 Itoh Z, Takahashi J. Periodic contractions of the canine gallbladder during the interdigestive state. Am J Physiol 1981; 240: G183-9.

19 Svenberg T, Christofides ND, Fitzpatrick ML, et al. Interdigestive biliary output in man: relationship to fluctuations in plasma motilin and the effect of atropine. Gut 1982; 23: 1024-8.

20 Thompson DG, Ritchie HD, Wingate DL. Patterns of small intestinal motility in duodenal ulcer patients before and after vagotomy. Gut 1982; 23: 517-23.

21 Shaffer EA, McOrmond P, Duggan H. Quantitative cholescintigraphy: assessment of gallbladder filling and emptying and duodenogastric reflux. Gastroenterology 1980; 79: 899-906.

22 Colmer MR, Owen GM, Shields R. Pattern of gastric emptying after vagotomy and pyloroplasty. $\mathrm{Br}$ Med J 1973; 2: 448-50.

23 Howlett PJ, Sheiner JH, Barber DC, et al. Gastric emptying in control subjects and patients with a duodenal ulcer before and after vagotomy. Gut 1976; 17: 542-50. 